\title{
Sustainable Policy? A Public Debate about Nature Development in the Netherlands
}

Citation for published version (APA):

Bijker, W. E. (2004). Sustainable Policy? A Public Debate about Nature Development in the Netherlands. History and technology, 20, 371-391. https://doi.org/10.1080/0734151042000304349

Document status and date:

Published: 01/01/2004

DOI:

10.1080/0734151042000304349

Document Version:

Publisher's PDF, also known as Version of record

\section{Please check the document version of this publication:}

- A submitted manuscript is the version of the article upon submission and before peer-review. There can be important differences between the submitted version and the official published version of record.

People interested in the research are advised to contact the author for the final version of the publication, or visit the DOI to the publisher's website.

- The final author version and the galley proof are versions of the publication after peer review.

- The final published version features the final layout of the paper including the volume, issue and page numbers.

Link to publication

\footnotetext{
General rights rights.

- You may freely distribute the URL identifying the publication in the public portal. please follow below link for the End User Agreement:

www.umlib.nl/taverne-license

Take down policy

If you believe that this document breaches copyright please contact us at:

repository@maastrichtuniversity.nl

providing details and we will investigate your claim.
}

Copyright and moral rights for the publications made accessible in the public portal are retained by the authors and/or other copyright owners and it is a condition of accessing publications that users recognise and abide by the legal requirements associated with these

- Users may download and print one copy of any publication from the public portal for the purpose of private study or research.

- You may not further distribute the material or use it for any profit-making activity or commercial gain

If the publication is distributed under the terms of Article $25 \mathrm{fa}$ of the Dutch Copyright Act, indicated by the "Taverne" license above, 


\title{
Sustainable Policy? A Public Debate about Nature Development in the Netherlands
}

\author{
Wiebe E. Bijker
}

This article makes, first, a general argument for 'sustainable policies.' This argument will build on the observation that modern societies, of all political guise, find it difficult to cope with the challenges and opportunities posed by science and technology. Classical models of democracy do not seem to be sufficiently equipped to guide the political process in our highly developed societies. Second, this paper will discuss constructivist views on the development of technology in relation to society, and explore possible implications for democratization of technological culture. And finally, the article will present a particular case of experimentation with one alternative form of democracy. This experimental addendum to the existing political repertoires in the Netherlands was a public debate about the issue of 'nature development' or 'nature construction'- the making of new nature, for example by giving back some of the Dutch land to the water of the rivers Rhein and Maas.

Keywords: Social Constructivism; Democratization; Citizens' Participation; Public Debates; Nature Development

Environmental sciences have emerged as interdisciplinary meeting grounds for such scientific disciplines as biology, ecology, toxicology, chemistry and agricultural studies. They have taken on all the standard paraphernalia of established disciplines-journals, chairs, departments, and undergraduate and graduate programmes. Their methodological style is that of the natural sciences, although they frequently stand in the limelight of politics and policy making, and accordingly assume some of the associated responsibilities. In playing a political role, the environmental sciences often adopt the credo of sustainable development. ${ }^{1}$ My primary focus in this paper is not on the environmental sciences per se, nor on sustainable development in the standard sense of the

\footnotetext{
Wiebe E. Bijker is Professor of Technology and Society at the University of Maastricht. Correspondence to: Faculteit der Cultuurwetenschappen, Universiteit Maastricht, PO Box 616, NL-6200MD Maastricht, The Netherlands. Email:W.Bijker@Tss.Unimaas.nl
} 
term. The aim of this paper is to argue that the environmental sciences, in order to contribute to sustainable development, have to extend their interdisciplinary scope even wider: they have to join forces with studies in the field of STS ('science, technology and society') to produce knowledge that is relevant to and applicable in the politics of sustainable development. ${ }^{2}$ Thus, the focus of this paper is on sustainability, but on the sustainability of policy making: how to make policies that last; how to carry out societal discussions leading up to the public formulation and subsequent support of new environmental policies; how to manage science and technology in our modern technological culture?

The goal of this paper, then, is threefold. First, I want to make a general argument for 'sustainable policies,' for a politicization of technological culture. The argument will build on the observation that modern societies, of all political guise, find it difficult to cope with the challenges and opportunities posed by science and technology. Classical models of democracy do not seem to be sufficiently equipped to guide the political process in our highly developed societies. Second, this paper will discuss specific constructivist views on environmental politics. Finally, I will present a particular case of experimentation with one alternative form of democracy. This experimental addendum to the existing political repertoires in the Netherlands was a public debate about the issue of 'nature development' or 'nature construction'- the making of new nature, for example by 'giving back' some of the Dutch land to the water of the rivers Rhein and Maas.

\section{Politicization of Technological Culture}

Technology and science are back on the political agenda. After the 1950s, when they figured as instruments to rebuild Europe, and after the 1970s, when they appeared in nuclear disguise as a threat to democracy, now technology and science enter the stage in a much more ambiguous role. Partly they are recognized as the 'motor of the economy'-both as a core element of the knowledge base of a country and as a factor in creating employment in production and in research and development (R\&D). Some parts of society blame them as the main cause of pollution, and-when used to automate and rationalize production-as a cause of unemployment. And science and technology are not just back on the political agenda in the narrow sense of the word: as a policy instrument or in governmental strategy documents. They are back in politics 'on the street.' Technology and science create controversies about, for example, waste management, power stations, railway tracks and airport extensions, genetically engineered organisms or ecology management-and these controversies engage large parts of the population. Clashes between public groups, governmental agencies and professional politicians reverberate throughout society. One prominent issue that emerges with this renewed political prominence of science and technology is the issue of democracy and the question of which roles experts play in our modern 'high-tech' culture. In this paper, I will question the character of especially technology and its place in society, and the consequences of a new characterization of technology for the role of experts. I will argue that there are good reasons-based on empirical studies of technological 
innovation - to radically broaden the definition of experts. This will have implications for the politics of technological culture.

I use the term 'technological culture' to highlight that our modern, highly developed societies are infused with science and technology. In other words, our culture cannot be understood without taking into account the crucial role that science and technology play in constituting modern society. But we need to politicize this technological culture. In the next section, I will argue that science and technology are no neutral constituents of our culture, but value-laden; and they are just as much socially constructed as they are building society. Therefore, they should be subject to political debate: choices in the development and deployment of science and technology are neither innocent nor politically neutral. They are too crucial for the make-up of modern societies to leave them to the engineers and scientists.

I will assume, but not extensively argue, that my readers recognize that contemporaneous democratic models often fall short in handling controversial issues of technological culture in an adequate way. ${ }^{3}$ The various parliamentary systems, supported by expert agencies (such as the Food and Drug Administration and the Environmental Protection Agency in the USA, ${ }^{4}$ or the Health Council in the Netherlands) are frequently confronted with fierce public controversies-from infrastructural plans to genetic engineering, from nuclear waste management to the use of ICT in society. Nature development has been one such controversy in the Netherlands.

\section{Images of Technology and Science}

Discussions about the role of science and technology in society inevitably build on assumptions about the character of science and technology. I will argue that the predominant 'standard' image is flawed and should be substituted by a constructivist image. For reasons of clarity and brevity I will primarily focus on technology, but the argument about the standard and constructivist images of science is very similar. ${ }^{5}$

\section{The Standard Image of Technology}

Scientific knowledge, in the standard image of science, is objective, value-free, and found by specialists. Technology, similarly, is a rather autonomous force in society and technology's working is an intrinsic property of the technical machines and processes. ${ }^{6}$ The left column of Table 1 summarizes the standard image of technology.

Some of the implications of these standard images are positive and comforting. Thus, for example, scientific knowledge does appear as a prominent candidate for solving all kinds of problems. In the domain of political thought, this naturally leads to 'technocracy'-like proposals. In addition, it seems that technology is good in itself and independent of context. Of course, it can be applied negatively, but then the users are to be blamed, not the technology. The standard images also leave us with a few problems. For some problems, for example, we do not yet have the right scientific knowledge. Also, an adequate application of knowledge is, in this view, a separate problem. The role of experts is problematic in a specific way: how can experts be recognized by 
Table 1 Standard and Constructivist Images of Technology

\begin{tabular}{|c|c|}
\hline Standard view of technology (and society) & Constructivist view of technology (and society) \\
\hline $\begin{array}{l}\text { Clear distinctions between the political and the } \\
\text { technical domain }\end{array}$ & $\begin{array}{l}\text { Both domains are intertwined; what is defined } \\
\text { as a technical or as a political problem will } \\
\text { depend on the particular context }\end{array}$ \\
\hline $\begin{array}{l}\text { Difference between 'real science' and 'trans- } \\
\text { science* }\end{array}$ & $\begin{array}{l}\text { All science is value-laden and may-again } \\
\text { depending on the context-have implications } \\
\text { for regulation and policy; thus there is no } \\
\text { fundamental difference between 'real science' } \\
\text { and 'trans-science', 'mandated science', or } \\
\text { 'policy-relevant science' }\end{array}$ \\
\hline $\begin{array}{l}\text { Social responsibility of scientists and } \\
\text { technologists is a key issue }\end{array}$ & $\begin{array}{l}\text { Development of science and technology is a } \\
\text { social process rather than a chain of individual } \\
\text { decisions; political and ethical issues related to } \\
\text { science therefore cannot be reduced to the } \\
\text { question of social responsibility of scientists and } \\
\text { technologists }\end{array}$ \\
\hline
\end{tabular}

Technology develops linearly, e.g. conception $\rightarrow>$ invention $\rightarrow$ innovation $\rightarrow$ diffusion

Distinction between technology's development and its effects

Clear distinction between technology development and control

Clear distinction between technology stimulation and regulation

Technology determines society, not the other way around

Technology is an exogenous variable in neoclassical economics

Social needs as well as social and environmental costs can be established unambiguously
Technology development cannot be conceptualized as a process with separate stages, let alone a linear one

The social construction of technology is a process that also continues into what is commonly called its 'diffusion stage'; the (social, economic, ecological, cultural, ...) effects of technology are thus part of the construction process and typically have direct vice versa implications for technology's shaping

Technology does not have the contextindependent status that is necessary to hope for a separation of its development and control; its social construction and the (political, democratic) control are part of the same process

Stimulation and regulation may be distinguishable goals, but will often interfere with each other and need not necessarily be implemented separately

Social shaping of technology and technical building of society are two sides of the same coin

Technology is an endogenous variable in evolutionary economics

Needs and costs of various kinds are also socially constructed-depending on the context, they are different for different relevant social groups, varying with perspective

*The concept 'trans-science' was introduced by Weinberg (1972). 
non-experts, how can non-experts trust the mechanisms that are supposed to safeguard the quality of the experts, and finally how can experts communicate that esoteric knowledge to non-experts? In the realm of technology, an additional problem is that new technologies may create new problems (which of course in due time will be solved by still newer technologies).

The solutions that are tried to solve these problems are well known, up to the point of being trivial: more scientific and technological research, peer review, scientific expert advisory committees and technology assessment. But it is equally clear that these 'solutions' do not offer as complete a disappearance of problems as the standard image of technology makes one hope for. In the next section, I will present an alternative image of technology, with some implications for an analysis of technology and democracy.

\section{The Constructivist Image of Technology}

Since the 1980s, sociological and historical studies have developed a constructivist analysis of technology in contrast to the standard image of technology that was largely 'technological determinist.' The idea that technology is socially shaped, rather than an autonomously developing force in society or a primarily cognitive development, is not entirely new, but its present momentum and precise formulation are quite recent. Social shaping models stress that technology does neither follow its own momentum, nor a rational goal-directed problem-solving path but is instead shaped by social factors. (See Table 1 for a summary of standard and constructivist images of technology.)

In the social construction of technology approach (SCOT), 'relevant social groups' are the starting point. ${ }^{7}$ Technical artefacts are described through the eyes of the members of relevant social groups. The interactions within and among relevant social groups can give different meanings to the same. Thus, for example, a nuclear reactor may exemplify to a group of union leaders an almost perfectly safe working environment compared to building sites or harbours with very small chances of on-the-job-accidents. To a group of international relations analysts, however, the reactor may represent a threat through enhancing the possibilities of nuclear proliferation, while for the neighbouring village the chances for radioactive emissions and the (indirect) employment effects may strive for prominence. As a workplace, the technology is succeeding quite well; whereas as a source for international tension or as an environmental hazard, it may be evaluated quite differently. This demonstration of interpretative flexibility is a crucial step in arguing for the feasibility of any sociology of technology - it shows that neither an artefact's identity, nor its technical 'success' or 'failure', are intrinsic properties of the artefact but subject to social variables.

The next step is to describe how artefacts are indeed socially constructed, thus tracing the increasing (or sometimes decreasing) degrees of stability of that artefact. The concept of 'technological frame' is proposed to explain the development of heterogeneous socio-technical ensembles, thus avoiding social reductionism. A technological frame structures the interactions between the actors of a relevant social group. A key characteristic of the concept is that it is applicable to all relevant social groups-technicians and others alike. ${ }^{8}$ It is built up when interaction 'around' a technology starts 
and continues. Existing practice does guide future practice, though not completely deterministically. The concept of 'technological frame' forms a hinge in the analysis of socio-technical ensembles: it sets the way in which technology influences interaction and thus shapes specific cultures, but it also explains how a new technology is constructed by a combination of enabling and constraining interactions within relevant social groups in a specific way.

This constructivist conception of technology is crucial for my discussion of democracy and technology. The argument involves two steps. First, I will argue that a constructivist analysis, in some form, is a condition sine qua non for any politics of technology. This results in stressing the malleability of technology, the possibility for choice, the basic insight that things could have been otherwise. However, technology is not only malleable and changeable, but can also be obdurate, hard and very fixed too. The second step, then, is to analyse this obduracy of socio-technical ensembles.

The constructivist perspective provides a rationale for a politics of technology. It does so by exemplifying the very possibility of a social analysis of technology. Demonstrating the interpretative flexibility of an artefact makes clear that the stabilization of an artefact is a social process, and hence subject to choices, interests, value judgements - in short, to politics. Without recognizing the interpretative flexibility of technology, one is bound to accept a technologically determinist view. A technological determinist view does not stimulate citizens' participation in processes of democratic control of technology, since it conveys an image of autonomy and of being uncontrollable. Apart from having a role in the public debate about socio-technical choices, to demonstrate the interpretative flexibility of socio-technical ensembles is also crucial in a more analytical sense. Since without such a perspective, an analysis of technology and society is bound to reproduce the stabilized meanings of technical artefacts and will miss many opportunities for intervention. The interpretative flexibility of technology will often not be obvious, and needs to be demonstrated in a rigorous way to escape the rather trivial level of observation that technology is man-made, and subject to many societal influences. The constructivist argument is that the core of technology-that which constitutes its working-is socially constructed. This is a way to take up the challenge of Langdon Winner's observation that 'artefacts have politics'-it is necessary to overcome the standard view of technology and society, in which 'blaming the hardware appears even more foolish than blaming the victims when it comes to judging conditions of public life'?

Let me now turn to the second step in the argument. To argue for the malleability of technology does not imply that we forget the solidity and momentum of sociotechnical ensembles. Such negligence might result in an equally counter-productive cultural-political climate, because it invokes too optimistic an expectation, which in turn may cause disillusions. A politics and a theory of socio-technology have to meet similar requirements here - a balance between malleability and obduracy in the first case, and a balance between actor and structural perspectives in the second. Sociotechnical ensembles do not only have interpretative flexibility, they can also be fixed, and obdurate-and they will accordingly function in the societal power struggles over technology. 
Elsewhere, I have distinguished two aspects of power-a micropolitics of power, in which technologies may be used as instruments to build up networks of influence, and a semiotic power structure, which results from these micropolitics and constrains and enables actors. ${ }^{10}$ The semiotic power originates from the fixity of meanings, which is built-up during the formation of a technological frame as a result of the micropolitics of relevant social groups. The relevant social groups, in building up the technological frame, have invested so much into the key technology that this technology's meaning becomes fixed-it cannot be changed easily, and it forms part of an enduring network of practices, theories and social institutions. From this time on, it may indeed happen that, naively speaking, the technology 'determines' social development. Such an'exemplary' socio-technical ensemble is, at the same time, the result of micropolitical interaction processes and one of the elements of a semiotic power structure. A socio-technical ensemble can also be an important boundary-creating instrument. Then it functions on the border between two relevant social groups, often especially in the hands of actors with a low inclusion in the respective technological frames.

For the low included actors such an artefact presents a 'take it or leave it' choice: they have no chance of modifying the artefact when they 'take' it, but life can go on quite well when they 'leave' it. For the highly included actors, on the contrary, there is no life without the exemplary artefact, but there is a lot of life within it. The obduracy of artefacts as boundary objects for low included actors consists in this 'take it or leave it' character. For such actors, there is no flexibility; there is no differentiated insight; there is only technology, determining life to some extent and allowing at best an 'all or nothing' choice. This is the obduracy of technology that most people know best. This is the kind of obduracy that gives rise to technological determinism. For high-included actors obduracy of technological ensembles presents itself as the technology being all-pervasive, beyond questioning, and dominating thoughts and interactions.

Artefacts as boundary objects result in obduracy because they link different relevant social groups together into a semiotic power structure. Making the 'take-it' choice with respect to such an artefact results in being included into such a semiotic power structure. This implies being subject to power relations that one would otherwise-in the case of a 'leave it' choice - be immune to. Someone who buys a car, for example, is thereby included in the semiotic structure of automobiling: cars-roads-rules-jamspetrol prices-taxes. This will result in this automobilist exerting power, for example by using the car during rush hour and thereby contributing to a traffic jam, but will also make her subject to the exertion of power by others - the traffic jam again. Without a car however, jams and oil prices simply do not matter. Artefacts as exemplars result in obduracy because they constitute to an important degree the world in which one is living. This also implies inclusion in a semiotic power structure, but with different possibilities and effects. Many of the power interactions are now in terms of the exemplary artefact. Leaving the car standing is less likely an option, but changing one's driving hours or routes (to beat the jams), changing from gasoline to diesel or liquid gas (to beat the taxes), or changing to a smaller car (to reduce parking problems) are possibilities. 
In a constructivist perspective on technology, socio-technical ensembles have at least these two types of obduracy. It is with this framework in mind that I now return to the political dimensions of our technological culture.

\section{The Politics of Technological Culture: In Need of Analysis and Experimentation}

In the previous section, I introduced a new conception of power to enable me to analyze the politics of technological culture. By this concept, I can make sense of the ways in which humans change the world, including technology, and of the ways in which technology has an impact on the world, partly by exerting power over humans. This concept, for example, can help us to make sense of the NIMBY phenomenon. ${ }^{11}$ When a particular socio-technical ensemble such as a waste incinerator or a new nature resort is presented, people may react differently, depending on their inclusion in the specific technological frame. Those with a low inclusion either will accept it without much comment or will completely oppose it. With the increased arsenal of micropolitical instruments that citizens in modern societies have, it now often will be the latterand politicians then accuse them of NIMBY-ism. Only when people have a relatively high inclusion, the socio-technical ensemble may acquire that other form of obduracy. For those people, the necessity of waste incineration is clear, and they appreciate that it can be realised in various ways with each its specific advantages and disadvantages. By engaging in a discussion about the details of the plan, these highly included citizens already accept it implicitly, and in return may influence its design.

Two very different conclusions can be drawn: one cynical in terms of power politics, and the other more positive in terms of a democratization of technological culture. The cynical conclusion is that for manoeuvring a particular project around potential opposition, this opposition should be granted some minimal form of participation: just enough to increase their inclusion so as to get the plan accepted. Participation then becomes an opinion-moulding device rather than an opportunity for modifying the design. The positive conclusion is that when one is prepared to allow true involvement of social groups in the design of the project, the project is more likely to be accepted, although probably in revised form.

It is against this background of experimenting with citizens' involvement in the design of socio-technical ensembles, that the public debate on nature development was conceived. I will first explain why 'nature development' is an appropriate case to study the politics of technological culture, and then outline the experimental character of the public debate.

\section{Nature Development: A Public Controversy Involving Science and Technology}

'Nature development' as a central concept for Dutch environmental policy was formulated in a governmental document in $1981 .^{12}$ Although its meaning is still evolving, it is generally taken to imply the creation of large nature reserves in which natural processes can develop in an unrestrained way. 
In its brief history, nature development arouse excited enthusiasm as well as fierce opposition. More than hundred nature development projects are under way now in the Netherlands, and in the next 30 years an area of some $7000 \mathrm{~km}^{2}$ is planned to be part of this 'ecological main structure' (see below). In some instances, however, opposition was so fierce (including physical violence) that nature development projects had to be cancelled. The dividing lines of the controversy potentially ran through all groups in society, although farmers were the main opponents of the new nature development plans. Until the public debate was held however, most discussions went on among the various groups of scientists and stakeholders, without involvement of the general public.

The ideas and practices of nature development are squarely built on environmental sciences and technologies. The aim of Dutch environmental policy became to create a sustainable ecosystem that is typical for the Netherlands. To operationalize this 'typical', the concept 'ecological reference' was developed. An ecological reference of a particular domain is a reconstruction of the natural environment in that domain, based on contemporaneous and historical data about that domain and similar domains elsewhere. Humans play a very limited role in such a reference. This implied that virtually all Dutch landscapes and ecosystems, which had been human-made at least since the 19 th century, did not meet this reference. Consequently, long extinct species such as the wolf and bison were to be introduced, while imported species, such as specific trees, had to be banished. A second implication of adopting the ecological scientific perspective was the need for large, interconnected areas. Large areas are necessary, ecologists argued, to realise as close an approach to the ecological reference by self-regulating ecological processes. To allow the exchange of plant and animal species, the various nature development domains need to be inter-connected. This led to the definition of an 'Ecological Main Structure' (ecologische hoofdstructuur). This Ecological Main Structure will form the backbone of Dutch nature, running from the south to the north of the country, and encompassing some $7000 \mathrm{~km}^{2} .{ }^{13}$ Another crucial concept in ecological restoration is 'nature valuation': the attribution of a value to specific forms of nature. ${ }^{14}$

Nature development builds on technology too. Bulldozers create dunes and ditches, and dredging ships model the rivers. With hydrological techniques, the ground water level is controlled. Agricultural techniques are employed to select plant and animal species that will populate the specific ecology. Stretching the definition of 'technology', business management and accountancy technique are used to settle the financial compensation for farmers and house owners who are obliged to move out. A complicated political-economic arrangement was agreed upon between the private pebble dredging companies and governmental agencies: the companies were allowed to exploit the river (and actually get out more stone than environmentalists wanted to allow. them), in return for financing a large part of the safety measures to prevent flooding.

\section{The Public Debate as an Experiment}

In 1994, the Deputy Minister of Education and Science installed, under the aegis of the Rathenau Institute, a 'Platform Science and Ethics' for an experimental period of three 
years (later to be extended with a fourth year). ${ }^{15}$ Its mission was to stimulate and shape public discussion and debate about ethical issues of science and technology. Ethics was used in a broad sense: all kinds of normative issues could be addressed. The Minister stressed societal aspects and interaction with society.

The Platform Science and Ethics organized three large public debates, on predictive genetic research, nature development, and information and communication technology. ${ }^{16}$ The first was modelled after the Danish consensus conferences and the third after a citizens' jury. The public debate on nature development was in many ways different from existing forms of public participation. ${ }^{17}$

The public debate on nature development was experimental in four ways. First, it was as experimental as the other two public debates: not formally built into the Dutch political structure, but part of the temporary activities of the Platform. Second, the topic was not primarily generated by Dutch politics or by societal unrest. "Nature development: why and how?' was deliberately chosen with the experimental aim of the debate in mind. Criteria to guide this choice were: an important role for science and technology, the presence of new scientific insights, the existence of normative issues, societal relevance, and acute political interest. ${ }^{18}$ Third, as I will describe in more detail in the next sections, the nature development debate differed in several aspects from existing formats: a heterogeneous panel (of laypersons, stakeholders and scientists), freedom to set the agenda, and field trips to meet societal organizations and local practices 'in situ.' Finally, the debate was set up as a scientific experiment in the sense that it was co-organized with three university research groups, forming part of their respective research programmes. ${ }^{19}$.

\section{The Public Debate 'Nature Development: Why and How?'}

In this section, I will describe in more detail the public debate 'Nature Development: Why and How? 20 In the last and final section, I will analyze the public debate experiment from the perspective of 'sustainable policies' in a technological culture.

\section{The Public Debate's Open Agenda}

The constructivist perspective on science, technology and society implicates that there are no specific social groups in society that are a priori more important than other groups. In the 'standard view', it would have been scientists and engineers to whom we should give priority of speech on scientific and technical issues, but in the constructivist view there is no theoretical basis for that. This does not mean, of course, that all groups are equal. However, it does turn the theoretical question about the relation between groups into an empirical question: how do some groups make themselves more powerful than other groups, how do some gain access to the table, how do some succeed to influence the agenda. It does also mean that the normative question about the demarcation between science and non-science, which philosophers of science have asked, is substituted by an empirical question: how is 
the demarcation between science and other forms of knowledge drawn in daily practice? ${ }^{21}$ This question is not just empirically interesting-it is politically highly relevant. Constructivist students of science do not argue that science and technology do not have a specific merit of their own; on the contrary, they typically advocate that science and technology should be cherished and safeguarded for their special merit. ${ }^{22}$ But this merit is accomplished in social practice and not bestowed upon science by philosophers.

To take serious this point of non-prioritizing one group or perspective, implied that the agenda of the debate had to be open and not prescribed by, for example, the organizers. The agenda was indeed open in several ways. Although the subject matternature development - was fixed, the range of issues to be discussed was open. The panel could question the very necessity of nature development or even nature conservation (hence the 'why?' in the title), or it could limit itself to discussing various forms of nature development, or to focusing on the consequences of the governmental policy of nature development. The agenda was also open in the sense that the form of the final statement was unspecified and that no consensus was required (as would have been in a true 'consensus conference').

In practice, it proved quite difficult to exploit this openness. There were of course the organizational constraints (see below): most of the organization of the debate's process, including the provision of information to the panel and the field studies, had to be done long before the panel met for the first time. It also proved difficult to convince the panel members that the agenda really was so open. In due course, most panel members did recognise their being free in framing the discussion, but by that time, the agenda had been shaped to a large extent by the previous discussions within the panel. Nevertheless, in the end the panel did grow into quite a self-conscious and self-managing body, as became clear when the panel took its own decision about participating in a promotional TV manifestation of the World Nature Fund.

\section{Organizational Conditions}

The public debate not only was an open process for the panel members, but also to some extent for the organizers. Because they took the openness of the panel's agenda serious, the organizers could not settle all details in advance. This created some dilemmas, particularly in setting the practical conditions.

The total time frame has been fixed by the organizers. Meeting places, including hotels, needed to be reserved well ahead. Dates had to be set in advance to allow panel members and contributing groups and experts to synchronize their own diaries. Some basic choices as to the forms of information presentation were also made in advance. This for example included the first weekend and four field studies (see below), which had to be organized previous to the first meeting of the panel.

We considered to provide each panel member with a small (for example, $5 \mathrm{k}$ ) budget to hire scientific expertise. This would have given the panel members an opportunity to ask scientists to carry out small research projects for them-and bigger ones when they joined their budgets. It would have been a true broadening of the panel's freedom, 
when the members could have formulated their own research questions, for anything from laboratory research to literature reviews or sociological surveying. However, budget constraints and organizational problems (especially related to time management) prevented the realization of this plan.

One point where the panel could and did take an initiative to change the organizational set-up was the timing of internal discussions. During the process, the panel claimed more time for internal discussions than the organizers had scheduled in advance. This was realised by changing the agenda of meetings, and by including an extra meeting of some representatives from the panel members. (An extra meeting of the complete panel could not be organized due to diary problems of the individual members.)

\section{A Heterogeneous Panel}

The general practice in organizing consensus conferences, citizens' juries, and other new forms of public participation about science and technology policy, is to set a lay panel apart from scientific and technical experts. Although there are good arguments for such practice, this separation can also be criticized. Work in STS, and more specifically SSK, has blurred the distinction between scientific and other forms of knowledge, as I mentioned previously. For that reason, we decided to experiment with a heterogeneous panel in this nature development debate.

Choosing for a heterogeneous panel does not imply a denial of the differences in expertise between the various panel members. However, the organizers wanted to avoid a one-dimensional differentiation between non-scientific laypersons and scientific experts. In line with the constructivist view of science and technology, the variety of expertise that is relevant for a complex issue such as nature development was recognized. One implication was that the definition of expertise had to be rather open.

Through advertisements in national and regional newspapers people were invited to participate in the panel. Interested candidates should write a letter explaining their background and motivation. From 200 applicants, the Platform selected 32 panel members. Using the applicants' self-characterizations, a panel was constituted of $50 \%$ non-experts, $25 \%$ stakeholders, and $25 \%$ scientists. In addition, heterogeneity in terms of age, gender, education level, and social and regional background was sought. Panel members received full costs reimbursements, but no honorarium.

It was interesting - and indeed a confirmation of the basic assumption about the relevance of various forms of expertise--to see the changing and developing positions of different members in the panel. In the course of the panel's proceedings, individual members acquired a specific 'expert status' that did not simply relate to their educational degree or scientific training.

\section{Information Gathering}

For the functioning of the public debate, the gathering of new information by the panel is crucial. In this case, the heterogeneity of the panel could have been a problem, but in 
the end turned out to be an advantage. The initially self-proclaimed non-experts could have felt intimidated by the scientists and stakeholders in the panel, and thus hesitate in asking questions and seeking information that the 'experts' already might have. It worked out the other way: communication within the panel developed in a balanced way and the 'experts' helped the 'non-experts' to digest information. ${ }^{23}$

The other evident problem was the open character of the agenda. To what extent should the organizers organize and pre-structure the information? It was impossible to leave the preparation of the information phase until after the panel had been convened for the first time. This was not only because of practical reasons (the restricted time frame, for example), but also because of the heterogeneity of the panel. The 'non-expert' panel members could not be expected to explicate their needs for information right at the beginning, and domination by the scientists and stakeholders would have been likely. However, preparing information meant a dilemma for STS informed organizers: which criteria to adopt when selecting articles for the reader, speakers for the seminars, and simulation or role-playing games for the workshops?

We tried to solve this problem in two ways: first, by orchestrating many different voices and views in the presentation of information on and assessments of nature development; and, second, by creating an additional information market, which the panel members could influence. The panel was involved in planning the market's programme when it met for the first time, and panel members could individually seek out specific sources for information during the market itself. This resulted in a four-stage process for the public debate: an orientation weekend, an information market, a field study and the final conference. ${ }^{24}$ The first three stages I shall describe in this section, the final one in the next.

The orientation phase (8-9 March 1996) was aimed at getting to know each other, and at providing a basic introduction of the issues by lectures, a simulation game, films, panel discussions and workshops. These various information sessions also allowed the panel members to assess each other's specific expertise. At various moments during this weekend, the panel spends time at identifying the key issues and at formulating more precisely the public debate's agenda. Panel members also could ask for additional organizations to be invited to the next phase of the information market.

During the information market (30 March 1996), presentations by action groups, organizations, and stakeholders were held. Because the panel felt they did not have enough internal discussion time during the first weekend, two additional sessions for panel deliberation were scheduled at the beginning, and the end of the day. The rest of the day, the panel members could wander individually past the market stalls of the various organizations. At various moments during the day's programme, plenary debates were staged between two opposing organizations. These were selected by the organizers to bring out some of the hidden conflicts in the nature development debate. These staged plenary discussions also served to occasionally 'shake-up' the social interaction at the market.

The field studies (26 April 1996) were an important innovative element in this public debate. The panel was divided in four groups of eight members. Each group made a daylong visit to one nature development project in the Netherlands: Gaasterland (in 
Friesland, northern part of the Netherlands), Goudplevier, (in Drente, northern part of the Netherlands), Bentwoud (Holland, western part of the Netherlands), Grensmaas (Limburg, southern part of the Netherlands). A typical programme started with the arrival of the panel members at one railway station. A small conference bus brought the group to a reception by the provincial authorities, where they listened to several introductions about the area and the project. Then the group travelled to the area, where a long walk under guidance of the nature developers followed. Additional meetings were scheduled with opposition groups and stakeholders, either during the walk or during lunch and coffee breaks in restaurants. All organizations and individuals involved in (or opposing to) the nature development project were invited for drinks at the end of the day. After the reception, the panel members had dinner among themselves, to draw conclusions and to further the discussion towards the final phase.

\section{Formulating the 'Concluding Statement'}

During the second phase, the panel had tried to insert an extra meeting between the third and the fourth phase. Because of timing problems, it proved impossible to organize a full panel meeting. Instead, the panel decided that each field study group would send one representative to a small co-ordination meeting. Input into this meeting were the four reports of the field studies, and individual statements that each panel member mailed as first formulation of her/his opinion as to what the final declaration should contain. The small working group drafted a text that was to form the starting point for the final meeting.

The final meeting and presentation of the public debate's outcome (31 May and 1 June 1996) was advertised in national and regional newspapers, and relevant organizations were invited specifically. The panel's deliberations were held on Friday afternoon and evening. During the night, the concluding statement was drafted. The panel's declaration was publicly presented at the conference on Saturday.

The formulation of the concluding statement also posed some principle problems. Here was a risk of splitting the panel along dividing lines between members with and without writing experience. We tried to solve this by providing the panel with four 'writers': STS scholars with some affinity with the relevant issues but basically with the assignment to provide as neutral as possible a 'writing tool' for the panel.

The organizers provide a 'technical chairperson' (Wiebe Bijker), who has to help the panel in reaching a final statement in time while maintaining as open a discussion as possible, to which all panel members can contribute as they wish. The chair is frequently corrected when he tries to summarize conclusions: the panel clearly has taken control of the process. During a series of plenary and group discussions, the various sections of the final statement are discussed, and keywords agreed upon. ${ }^{25}$ It is already past midnight when the plenary meeting is resolved, and the writers start to work. When the others wake up in the morning, the final editing is still going on, but a readable draft can be presented over breakfast. There is too little time to read and discuss the full text (13 pages, and three pages of appendices). Members only read the conclusions and can agree to those. 
But then, later that morning during the plenary presentation at the Saturday conference, the panel makes a remarkable switch and presents itself to the public as a homogeneous and solid body without notable internal differences of opinion. After the plenary debate about the final statement with the public at the conference, the panel resumes its own internal discussion for the last time. Although the final statement worked well during the conference, some members complain that they cannot see the statement as their own, and thus cannot subscribe to it. The discussion that follows focuses on the status of the statement, rather than on its content. A crisis develops: not all panel members can agree to the statement. This is resolved by defining the final statement as the result of long process that all 32 members of the panel collectively followed through, and not as a consensual declaration that each individually subscribes to. In the final text, this is described as follows:

\footnotetext{
The contents of the final statement will make clear that the panel has not primarily been aiming at reaching a consensus, in the form of a single vision shared by each member in every detail. The final statement is a product to which all panel members contributed in their own way. Its general thrust is subscribed to by all. ${ }^{26}$
}

With this agreement, the panel can come out again and officially present its final statement to a Member of Parliament.

\section{Sustainable Policies in a Technological Culture}

For sustainable politics, a politics that has lasting and substantial support in society, democratic mechanisms are needed that connect political decision making to public and societal concerns and debates. For sustainable politics in a technological culture, these democratic mechanism should pay due respect to the scientific and technological aspects of political issues. In the second section I have argued that this problem cannot be solved by naively 'inserting' scientific and engineering expertise into the political process, since what exactly counts as such expertise is part of the political process. This does not imply that scientific and technological expertise should not play an important role in the political process. But the implication is that democratic mechanisms should be flexible and open, so as not to fix various definitions in too early a stage of the political process. More specifically, the character of expertise should not be assumed a priori as being scientific or otherwise. As an illustration of the latter, I shall first discuss some examples of how during the public debate on nature development the boundary between science and non-science was demarcated. Then I will return to the issue of flexibility and openness and summarize the key aspect of the public debate as an open learning process.

\section{Demarcating Science from Non-Science in the Public Debate on Nature Development}

To be sure, the concluding statement did contain explicitly scientific and non-scientific propositions. In the section 'considerations,' for example, the first paragraph explicitly makes the scientific diversity argument: 'Biodiversity decreases. On the long term, this 
disappearance of certain species can have large effects on the whole ecosystem. ${ }^{27} \mathrm{But}$ this is matched with considerations that draw on completely different arguments and values:

The link between humans and environment is disturbed. On the one hand, people need a pleasant living environment to have a stable life. People consider nature beautiful. They value nature to relax and to gain new energy. On the other hand, city life has alienated people from nature. Everyone thinks nature is important, but often the insight in natural processes is lacking. Hence the respect for nature is diminishing, and people do not feel responsible for nature anymore. ${ }^{28}$

So, how is the boundary between these two kinds of arguments and considerations drawn? How is science demarcated from non-science? During the debate, science was made to stand out as different from non-science at three levels: at the micro level within the panel, at a meso level within nature conservation organisations, and at the macro level of Dutch national politics.

At some moments in the discussion, the boundary between science and nonscience, or rather between scientists and non-scientists, was simply drawn by having a university degree or not. 'That is a scientific argument,' someone labelled a particular remark from a university graduate's mouth. More strategically, the panel sometimes chose to use scientific words deliberately. Thus, 'biodiversity' played a central role in the concluding statement. In addition, the panel recognized some skills as specifically scientific. Thus, it was readily agreed that the ecologists would elaborate the new taxonomy of types of nature, and present part of the argument in quantitative terms in tables. Finally, the line between science and non-science was also drawn 'from the other side': by claiming space for emotional arguments, 'because they are not scientific.'

At the meso level-of the panel's external relations--there was deliberate usage of scientific vocabulary to command legitimation, for example, quantitative tables and a taxonomy of concepts of nature. It is important-in the context of this article-to note that the panel did not seek to be as scientific as possible. The panel had quite a differentiated and specific view of where 'being scientific' would have a positive effect and where a negative. Thus, they did use scientific vocabulary at some point in the statement, but at the same time they decided-after a long discussion, consciously weighing these effects - to send a non-scientist as their representative to a nationally broadcasted TV debate. This decision was to support the panel's conclusion on this issue of the role of science: "the panel observes that discussion on nature policy is dominated too much by biologists and ecologists. ${ }^{29}$

At the macro level, the organizers did the most important demarcating work. The key mission of the organizing Platform Science and Ethics (cf. note 16) was exactly to mediate between scientific expertise and non-scientific arguments and values. As I described in this article, the goal of this debate was to study a controversy that did indeed involve science and technology. In addition, the central idea in designing this debate was to use a heterogeneous panel with scientists and non-scientists. So, in the very first formulation of the objectives and the means of the public debate on nature development, the Platform drew on a demarcation between science and non-science. 
In selecting the panel, this demarcation was operationalized by using the candidates' own demarcation criteria as to whether they considered themselves scientist or not. In practice, this boiled down to whether someone had graduated from a university.

\section{The Public Debate as an Open Learning Process}

New forms of politicization of technological culture should be shaped as open learning processes. ${ }^{30}$ This phrase highlights three crucial elements for new forms of sustainable politics in a technological culture:

- open: policy goals and priorities are not fixed at the outset, but are amenable to revision during the debate (or whatever new form of democratic deliberation);

- learning: the debate has means to record and make widely available the arguments, decisions, results, successes and failures of the discussion process; and

- process: the focus is not as much on the products of the debate, as it is on the process of reaching (not necessarily consensual) conclusions.

When designing new experiments in the politicization of technological culture, these elements can be checked by a variety of indicators. I mention a few here.

Qualitative indicators of the open character of the process are the variety of actors involved; the existence of procedures to guarantee outside influence; and the existence of procedures to take into account the views of people and societal sectors that are potentially effected by the considered policies. For adequate learning, qualitative indicators are the openness of accounting and reporting procedures and styles; the development of trust and mutual recognition and appreciation among participants of each other's specific competencies; the level of reflexivity (with regard to content), that is, the willingness among participants to discuss, recognize and (re)consider implicit assumptions and limitations in each position, argument or approach. Indicators for the process character are: a tolerance for failures; regular evaluation of progress and adjustment of goals; flexibility of procedures; the level of reflexivity (with regard to process), that is, the willingness to discuss whether procedures in- or exclude relevant groups, favour or suppress specific positions or arguments; and a general transparency of the policy dialogue process.

\section{Conclusion: Requirements for Sustainable Politics}

'Sustainable politics' are politics that are relatively stable and can be sustained over a period of time in a democratic society. For sustainable politics in a technological culture, a politicization of this technological culture is necessary: the role of science and technology in making society should be unveiled and put on the political agenda. The political dimensions of scientific and technological developments need to be made clear. I have argued in this article that for such a politicization of technological culture a constructivist image of science and technology is helpful.

The next step then, is to develop new forms of democratic deliberation in which this politicization of technological culture is translated into institutional form. I have 
discussed an experiment with one such form-the Dutch public debate on nature development. More generally I have argued in the previous section that new institutional forms of sustainable politics should have the characteristics of an open learning process.

\section{Notes}

[1] This phrase was first introduced in the 1987 report by the World Commission on Environment and Development. See also Jamison and $\varnothing$ stby, Public Participation and Sustainable Development, for a European project on public participation in sustainable development policies, and Rogers, 'Whither Public Participation in Technology?,' reporting on a conference on this subject.

[2] For a similar argument, but primarily directed in the other direction (that is, 'that the environment should be recognized as a key site for social studies of science'), and providing a comprehensive literature review, see Yearley, 'The Environmental Challenge to Science Studies.' A good overview of the STS field is given in the Handbook of Science and Technology Studies (Jasanoff et al., Handbook of Science and Technology Studies).

[3] For an elaboration of this claim, see for example part VII ('Science, Technology, and the State') in Jasanoff, Handbook of Science and Technology Studies, Feenberg and Hannay, Technology and the Politics of Knowledge, and Sclove, Democracy and Technology.

[4] See Jasanoff, The Fifth Branch. Science Advisers as Policymakers, for an analysis of these expert agencies.

[5] For a good introduction into the "sociology of scientific knowledge' (SSK), see Collins, Changing Order: Replication and Induction in Scientific Practice.

[6] See for a critical discussion of the standard image of science: Latour, Science in Action: How to Follow Scientists and Engineers Through Society. For an overview of standard and alternative views on technology, see Bijker, Of Bicycles, Bakelites and Bulbs.

[7] See Bijker, Of Bicycles, Bakelites and Bulbs, for a full account of this approach; also translated into Italian (Bijker, La bicicletta e altre Innovazioni).

[8] It is on this point that 'technological frame' differs crucially from concepts such as Kuhn's 'paradigm' or Dosi's 'technological paradigm.'

[9] Winner, The Whale and the Reactor, 20.

[10] See the last two chapters in Bijker, Of Bicycles, Bakelites and Bulbs, for a fuller discussion.

[11] NIMBY: Not In My Back Yard. See Piller, The Fail-Safe Society.

[12] Tweede Kamer der Staten Generaal, Structuurschema Natuur en Landschapsbehoud: Deel A. TK 1980-1981, 16820 nrs. 1-2. For a more detailed discussion of the history of nature development, see Windt et al., 'De wortels en dilemma's van natuurontwikkeling.' Windt, En dan: wat is natuur nog in dit land? describes the broader history of nature conservation and development in the Netherlands between 1880 and 1990. Chapter 4 by Jamison et al., The Making of the New Environmental Consciousness, gives a broad overview of the recent history of environmental politics in the Netherlands; see also Andringa and Schot, "Public Participation in Environmental Science and Technology'.

[13] This is more than $16 \%$ of the total surface of the Netherlands, about seven times as much as the total area of nature reserves in 1980 .

[14] See Swart et al.. 'Valuation Of Nature In Conservation And Restoration,' for a comprehensive discussion of and new model for nature valuation.

[15] The Rathenau Institute is the Dutch equivalent of an Office of Technology Assessment. The addressee of its reports is parliament, but its agenda is formulated more independently than used to be the case for the American OTA. 
[16] The Platform Science and Ethics also organized some smaller debates, for example on the choice of sex and on privacy; and several discussions within professional associations. For an overview of the Platform's activities, see its evaluation report (Platform, Platform Wetenschapen Techniek).

[17] For a brief introduction of the 'consensus conference' procedure, see Guston, 'Evaluating the First US Consensus Conference.' See also Rowe and Frewer, 'Public Participation Methods,' who propose criteria for evaluating such new forms of public participation.

[18] Topics that were considered, but not chosen, related to energy, mobility, waste and the strengthening of river dikes.

[19] Henny van der Windt and Sjaak Swart (Science and Society Studies group, Biology Department, University of Groningen) focused on ecology issues and conceptual changes in nature conservation, management and development (Windt et al., 'De wortels en dilemma's van natuurontwikkeling'). Mieke Aarts and Hedwig te Molder (Department of Science Communication, Agricultural University of Wageningen) did a discourse analysis of some of the key discussions in the panel (Aarts and Molder, 'Spreken Over Natuur'). Wiebe Bijker, Thessa van Hoorn and Ger Wackers (Department of Technology and Society Studies, University of Maastricht) studied the public debate as an instance of democratization of technological culture. The latter group was also, with Prof. Nanne van de Poll (secretary and co-ordinator of the Platform Science and Ethics), responsible for the overall set-up of the debate.

[20] The book edited by Poll (Natuurontwikkeling: waarom en hoe?) (in Dutch) provides more details in appendices: the names of the panel members, the full text of the panel's final declaration, and all basic information about programming, lists of provided literature and the involved organisers.

[21] The most illuminating exemplar, for me, still is Karl Popper ( The Logic of Scientific Discovery; Conjectures and Refutations).

[22] The so-called 'science wars' in primarily the USA were built on this misreading. For a comprehensive discussion, see Gieryn, Cultural Botundaries of Science; see also the discussion in Social Studies of Science (Edge, 'Editorial Postscript').

[23] This is analysed in more detail by Wackers et al., 'Het natuurontwikkelingsdebat,' 51-5.

[24] Being in the Netherlands, we respected the Protestants' 'Sunday rest'. 'Weekend' thus meant Friday and Saturday.

[25] This phase in the process is critically evaluated by panel members. Most are dissatisfied with the Friday evening's discussion: too much time pressure and too little structure. An uneven input by panel members is criticized. Half of the panel members blame the chairperson, the other half compliment him (Poll and Glasmeier, Natuurontwikkeling).

[26] Panel on Nature Development, 'Slotverklaring Natuurontwikkeling,' 133-4. English translations are mine.

[27] Ibid., 135.

[28] Ibid., 135.

[29] Ibid., 140.

[30] We first developed this argument on the basis of this public debate on nature development (Wackers et al., 'Het natuurontwikkelingsdebat'), and later applied it to the problem of research and technology for developing countries (Bijker et al., EU-ACP Policy Dialogue on Research and Technology for Development).

\section{References}

Aarts, M. N. C., and Molder, H. F. M. t. 'Spreken over natuur, een discourse-analytische studie van een debat.' In Natuurontwikkeling: waarom en hoe? Verslag van een debat, edited by N. E. v. d. Poll and A. Glasmeier. Den Haag: Rathenau Instituut, 1997. 
Andringa, J. M., and Schot, J. 'Public Participation in Environmental Science and Technology: The Dutch National Experience, 1960s-1990s.' In Public Participation and Sustainable Development. Comparing European Experiences, edited by A. Jamison and P. Østby. Aalborg: Aalborg Universitetsforlag, 1997.

Bijker, W. E. Of Bicycles, Bakelites and Bulbs. Toward a Theory of Sociotechnical Change. Cambridge, MA: MIT Press, 1995.

—. 'Sociohistorical Technology Studies.' In Handbook of Science and Technology Studies, edited by S. Jasanoff, G. E. Markle, J. C. Petersen and T. Pinch. London: Sage, 1995.

Bijker, W. E. La bicicletta e altre Innovazioni. Milan: McGraw-Hill Libri Italia, 1998.

Bijker, W. E., C. Leonards, and G. Wackers. EU-ACP Policy Dialogue on Research and Technology for Development (RTD). Methodology for RTD Diagnostic Studies in ACP Countries. Maastricht: Universiteit Maastricht, 2000.

Collins, H. M. Changing Order: Replication and Induction in Scientific Practice. London: Sage, 1985.

Edge, D. 'Editorial Postscript.' Social Studies of Science 29, no. 5 (1999): $790 \rightarrow 9$.

Feenberg, A., and A. Hannay, eds. Technology and the Politics of Knowledge. Bloomington and Indianapolis: Indiana University Press, 1995.

Gieryn, T. Cultural Boundaries of Science. Credibility on the Line. Chicago, IL: The University of Chicago Press, 1999.

Guston, D. H. 'Evaluating the First US Consensus Conference: The Impact of the Citizens' Panel on Telecommunications and the Future of Democracy.' Science, Technology, \& Human Values 24, no. 4 (1999): 451-82.

Jamison, A., and P. Ostby, eds. Public Participation and Sustainable Development. Comparing European Experiences. Vol. 1. Aalborg: Aalborg Universitetsforlag, 1997.

Jamison, A., R. Eyerman, and J. Cramer. The Making of the New Environmental Consciousness. Edinburgh: Edinburgh University Press, 1990.

Jasanoff, S. The Fifth Branch. Science Advisers as Policymakers. Cambridge, MA: Harvard University Press, 1990.

- , G. E. Markle, J. C. Petersen, and T. Pinch, eds. Handbook of Science and Technology Studies. London: Sage, 1995.

Latour, B. Science in Action: How to Follow Scientists and Engineers Through Society. Cambridge: Harvard University Press, 1987.

Panel, N. 'Slotverklaring Natuurontwikkeling: waarom en hoe? (met drie bijlagen).' In Natuurontwikkeling: waarom en hoe? Verslag van een debat, edited by N. E. v. d. Poll and A. Glasmeier. Den Haag: Rathenau Instituut, 1997.

Piller, C. The Fail-Safe Society: Community Defiance and the End of American Technological Optimism. Berkeley, CA: University of California Press, 1991. Platform, W.e. E. Platform Wetenschap en Techniek. Evaluatie 1994-1997. Den Haag: Rathenau Insti-
tuut, 1997.

Poll, N. E. v. d., and Glasmeier, A. 'Natuurontwikkeling: waarom en hoe? Evaluatie van een debat'. In Natuurontwikkeling: waarom en hoe? Verslag van een debat, edited by N. E. v. d. Poll and A. Glasmeier. Den Haag: Rathenau Instituut, 1997. - eds. Natuurontwikkeling: waarom en hoe? Verslag van een debat. Den Haag: Rathenau Instituut,
1997 .

Popper, K. R. The Logic of Scientific Discovery. London: Hutchinson, 1959.

Conjectures and Refutations. London: Routledge and Kegan Paul, 1963.

Rogers, R. 'Whither Public Participation in Technology?' EASST Review 17, no. 4 (1998): 40-3.

Rowe, G. and Frewer, L. J. 'Public Participation Methods: A Framework for Evaluation.' Science, Technology, \& Human Values 25, no. 1 (2000): 3-29.

Sclove, R. E. Democracy and Technology. New York: The Guilford Press, 1995.

Swart, J. A. A., H. J. v. d. Windt, and J. Keulartz. 'Valuation Of Nature In Conservation And Restoration.' Restauration Ecology, 2001. 
Wackers, G., T. v. Hoorn, and W. E. Bijker. 'Het natuurontwikkelingsdebat: dilemma's van een open leerproces.' In Natutrontwikkeling: waarom en hoe? Verslag van een debat, edited by N. E. v. d. Poll and A. Glasmeier. Den Haag: Rathenau Instituut, 1997.

Weinberg, A. M. 'Science and Trans-science.' Minerva 10 (1972): $209-22$.

Windt, H. J. v. d. En dan: wat is natuur nog in dit land? Natuurbescherming in Nederland, 1880-1990. Amsterdam: Boom, 1995.

Windt, H. J. v. d., J. A. A. Swart, and R. Rabbinge. 'De wortels en dilemma's van natuurontwikkeling.' In Natuurontwikkeling: waarom en hoe? Verslag van een debat, edited by N. E. v. d. Poll and A. Glasmeier. Den Haag: Rathenau Instituut, 1997.

Winner, L. The Whale and the Reactor A Search for the Limits in an Age of High Technology. Chicago, IL: University of Chicago Press, 1986.

Yearley, S. 'The Environmental Challenge to Science Studies.' In Handbook of Science and Technology Studies, edited by S. Jasanoff, G. E. Markle, J. C. Petersen and T. Pinch. London: Sage, 1995. 